\title{
Decoration of reduced graphene oxide with rhodium nanoparticles for the design of a sensitive electrochemical enzyme biosensor for $17 \beta$-estradiol
}

\author{
Eloy Povedano ${ }^{\mathrm{a}}$, Fernando H. Cincotto ${ }^{\mathrm{a}, \mathrm{b}}$, Concepción Parrado ${ }^{\mathrm{a}}$, Paula Díez ${ }^{\mathrm{a}}$, \\ Alfredo Sánchez ${ }^{\mathrm{a}, *}$, Thiago C. Canevari ${ }^{\mathrm{c}}$, Sergio A.S. Machado ${ }^{\mathrm{b}}$, José M. Pingarrón ${ }^{\mathrm{a}}$, \\ Reynaldo Villalonga ${ }^{\mathrm{a}, *}$ \\ a Department of Analytical Chemistry, Faculty of Chemistry, Complutense University of MadridMadrid28040Spain \\ ${ }^{\mathrm{b}}$ Institute of Chemistry, State University of São PauloPO Box 780São CarlosSP13560-970Brazil

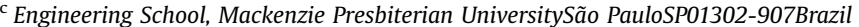

\section{A R T I C L E I N F O}

Article history:

Received 23 December 2015

Received in revised form 26 June 2016

Accepted 7 July 2016

Available online 7 July 2016

Keywords:

Biosensor

$17 \beta$-estradiol

Graphene oxide

Rhodium nanoparticles

Nanocomposite material

\begin{abstract}
A B S T R A C T
A novel nanocomposite material consisting of reduced graphene oxide/Rh nanoparticles was prepared by a one-pot reaction process. The strategy involved the simultaneous reduction of $\mathrm{RhCl}_{3}$ and graphene oxide with $\mathrm{NaBH}_{4}$ and the in situ deposition of the metal nanoparticles on the 2D carbon nanomaterial planar sheets. Glassy carbon electrode coated with this nanocomposite was employed as nanostructured support for the cross-linking of the enzyme laccase with glutaraldehyde to construct a voltammperometric biosensor for $17 \beta$-estradiol in the $0.9-11 \mathrm{pM}$ range. The biosensor showed excellent analytical

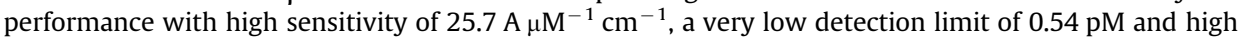
selectivity. The biosensor was applied to the rapid and successful determination of the hormone in spiked synthetic and real human urine samples.
\end{abstract}

(c) 2016 Elsevier B.V. All rights reserved.

\section{Introduction}

Nanomaterials engineering has greatly impacted bioelectroanalytical chemistry by providing a large variety of novel and advanced nanosized materials with well-defined morphology and physicochemical properties (Walcarius et al., 2013). These nanomaterials have been successfully employed as transducers for the design of novel, sensitive and reliable biosensor devices. Tailor made nanomaterials have been also widely employed as signalling and amplification tools for affinity-based electrochemical biosensors (Lei and Ju, 2012; Yáñez-Sedeño et al., 2015).

Among these, two dimensional nanomaterials have recently attracted great attention for designing electrochemical biosensors due to the unique thickness dependent physical and chemical properties of these materials (Kannan et al., 2015). In this sense, several 2D layered inorganic nanomaterials such as $\mathrm{MoS}_{2}, \mathrm{WS}_{2}$, $\mathrm{CuS}$ and $\mathrm{SnS}_{2}$ have been explored as transduction elements for bioelectroanalytical applications (Sarkar et al., 2014; Wang et al., 2014; Vasilescu et al., 2016; Yuan et al., 2014; Huang et al., 2015a,

\footnotetext{
* Corresponding authors.

E-mail addresses: alfredo_2sanchez@hotmail.com (A. Sánchez), rvillalonga@quim.ucm.es (R. Villalonga).
}

2015b; Yang et al., 2011). Mesoporous silica thin films have been also recently employed as two dimensional scaffolds for the assembly of label free electrochemical biosensors (Fernández et al., 2014; Saadaoui et al., 2015). However, graphene-based nanomaterials are, by far, the 2D nanomaterials more widely used for biosensing purposes (Araque et al., 2013; Khatayevich et al., 2014; Kailashiya et al., 2015; Borisova et al., 2015, Araque et al. 2014a; Lian et al., 2015). These 2D carbon nanomaterials have emerged as useful tools for bioelectroanalysis due to their unique electroconductive properties, large surface-to-volume ratio, flexibility, high mechanical and thermal stability, remarkable biocompatibility and low cost (Allen et al., 2009).

Despite these outstanding properties, high hydrophobicity and lack of chemical functional groups to be employed as linking points for the covalent immobilization of bioreceptors has limited the use of graphene as scaffold for the assembly of stable biosensing interfaces (Liu et al., 2012). These problems can be partially overcome by using graphene oxide (GO), a water soluble derivative with carboxyl groups at the sheet edges, and hydroxyl, epoxide and carbonyl groups on the graphene basal planes (Allen et al., 2009; Rourke et al., 2011). These oxygen functional groups confer hydrophilicity to the 2D nanomaterial, and can be easily employed as anchoring point for the further surface immobilization of biomolecules. Bioelectroanalytical potential of GO can be 
boosted by proper covalent and non-covalent decoration with metal nanostructures, yielding advanced nanohybrids and nanocomposites with improved electroconductive and catalytic properties (Mei et al., 2015; Zhao et al., 2015; Araque et al., 2014b; Boujakhrout et al., 2015).

In this work we describe the facile preparation of a novel GO nanocomposite by in situ non-covalent decoration of the 2D carbon nanomaterial with rhodium nanoparticles. The resulting nanocomposite was employed as coating material for glassy carbon electrode to construct an electrochemical laccase enzyme biosensor for the determination of $17 \beta$-estradiol. The steroid $17 \beta$ estradiol is a natural endocrine disrupting compound excreted by humans and animals, which has been classified as emerging contaminant due to its harmful effects on endocrine function of animals, humans and aquatic organisms (Ying et al., 2002). In fact, it has been previously reported that high amounts of $17 \beta$-estradiol may interfere with the normal physiological processes causing sexual abnormalities, a declined male birth rate, and even cancer development (Storgaard et al., 2006; De Assis et al., 2013). That is why the development of simple, sensitive, reliable and cost-effective analytical methods and devices for $17 \beta$-estradiol receives considerable attention. In this work we selected laccase as catalytic bioreceptor for the construction of the electrochemical biosensor due to the ability of this enzyme to recognize $17 \beta$-estradiol as substrate (Suzuki et al., 2003; Riva, 2006; Torres-Duarte et al., 2012).

\section{Materials and methods}

\subsection{Materials}

Single layer graphene oxide (GO), prepared according to Hummers method (Hummers and Offeman, 1958) was provided by Orion High Technologies (Spain). Laccase from Trametes versicolor (Lac, EC $1.10 .3 .2,10 \mathrm{U} / \mathrm{mg}$ ), $17 \beta$-estradiol, thionine, $\mathrm{RhCl}_{3}$, poly (ethylene glycol) diglycidyl ether, $\mathrm{NaBH}_{4}$ and glutaraldehyde were purchased from Sigma-Aldrich Co. (USA). All other chemicals were analytical grade.

\subsection{Electrochemical measurements}

A dual-channel Inbea potentiostat was used for amperometric measurements (Inbea Biosensores, Spain). Electrochemical impedance spectroscopy and voltamperometric experiments were performed by using a FRA2 $\mu$ Autolab Type III potentiostat/galvanostat (Metrohm Autolab B.V., The Netherlands). A conventional three-electrode system was employed in all electrochemical studies. The working electrode was a glassy carbon electrode (GCE, $3.0 \mathrm{~mm}$ diameter) modified with the graphene nanocomposite and the immobilized enzyme. $\mathrm{An} \mathrm{Ag} / \mathrm{AgCl} / \mathrm{KCl}$ ( $3 \mathrm{M}$ ) and a Pt wire were used as reference and counter electrodes, respectively. The measurements with the biosensor were carried out at $25^{\circ} \mathrm{C}$ in $1.0 \mathrm{mM}$ thionine solution in $0.1 \mathrm{M}$ sodium phosphate buffer, $\mathrm{pH} 7.0$ (working volume $10 \mathrm{~mL}$ ). Stock solutions of $1.0 \mathrm{mM} 17 \beta$-estradiol in ethanol were freshly prepared.

\subsection{Microscopy and spectrometric analysis}

Atomic force microscopy (AFM) experiments were performed with a SPM Nanoscope IIIa multimode microscope (Veeco Instruments Inc., USA). FT-IR spectra were acquired with a Nicolet Nexus 670/870 spectrometer (Thermo Fisher Scientific Inc., USA). Transmission electron microscopy (TEM) and high resolution transmission electron microscopy (HRTEM) measurements were performed with JEOL JEM-2000 FX and JEOL JEM-3000F microscopes, respectively (Jeol Ltd., Japan). Power X-ray diffraction (XRD) was performed with an X'Pert MRD diffractometer (PANanalytical B.V., The Netherlands). High resolution field emission scanning electron microscopy (FE-SEM) was performed with a JEOL JSM-6335F microscope (JEOL Ltd., Japan).

\subsection{Preparation of reduced graphene oxide-rhodium nanoparticles nanocomposite (rGO-RhNP)}

The nanocomposite material was prepared by dispersing $500 \mathrm{mg} \mathrm{GO}$ and $500 \mathrm{mg} \mathrm{RhCl}_{3}$ in $50 \mathrm{~mL}$ double-distilled water by ultrasound treatment during $30 \mathrm{~min}$. The mixture was heated to boiling under continuous magnetic stirring, and then $750 \mu \mathrm{L}$ of $1 \%$ $(\mathrm{w} / \mathrm{v})$ sodium citrate solution were added. The mixture was boiled for $5 \mathrm{~min}$ and then $100 \mathrm{mg} \mathrm{NaBH}$ in $5 \mathrm{~mL}$ water were added. The mixture was stirred under heating for other $30 \mathrm{~min}$, then cooled to room temperature and filtered. The resulting solid was repeatedly washed with water and ethanol, dried under vacuum at room temperature and kept dry until use.

\subsection{Preparation of the enzyme electrode ( $L a c / r G O-R h N P / G C E$ )}

To prepare the enzyme electrode, a GCE was polished to a mirror-like finish using $0.3 \mu \mathrm{m}$ alumina slurry and sonicated in distilled water and ethanol. The electrode was first coated with rGO-RhNP by depositing $10 \mu \mathrm{L}$ of a $0.5 \mathrm{mg} / \mathrm{mL}$ aqueous dispersion of the nanocomposite on the electrode surface and allowing drying. Laccase was further immobilized on the nanostructured electrode surface by dropping $10 \mu \mathrm{L}$ of $6.6 \mathrm{mg} / \mathrm{mL}$ enzyme solution

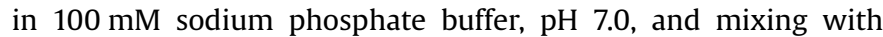
$10 \mu \mathrm{L}$ of $3 \%(\mathrm{v} / \mathrm{v})$ glutaraldehyde solution. The electrode was kept at $4{ }^{\circ} \mathrm{C}$ for $1 \mathrm{~h}$, then washed several times with cold $100 \mathrm{mM}$ sodium phosphate buffer, $\mathrm{pH} 7.0$ and finally stored in refrigerator until use.

\section{Results and discussion}

\subsection{Preparation and characterization of the transducer nanomaterial}

Scheme 1 illustrates the strategy employed to prepare the rGORhNP nanocomposite and to assemble the laccase amperometric biosensor for $17 \beta$-estradiol. First, the nanocomposite material was prepared through a one-pot scheme by reducing $\mathrm{Rh}^{3+}$ ions with $\mathrm{NaBH}_{4}$ in the presence of graphene oxide and sodium citrate. Through this process, citrate-capped Rh nanoparticles were rapidly formed and, at the same time, the epoxy and carbonyl residues on the GO planar sheets were transformed to hydroxyl groups.

The remaining oxygen functional groups (hydroxyl and carboxylate) could act as linking points for the non-covalent attachment (most likely by donor-acceptor interactions) of the Rh nanoparticles to the GO nanosheets, yielding a stable composite nanomaterial. The resulting product was easily dispersed in water due to the presence of carboxylic acid groups at the edge of the rGO sheets, as well as the non-covalent coating of Rh nanoparticles with citrate ions.

Fig. 1 show representative TEM and HRTEM images of the rGORhNP nanocomposite. Highly polydisperse sphere-like nanoparticles of $6.1 \pm 2.6 \mathrm{~nm}$ covering almost the entire GO surface was observed. TEM analysis also revealed that metal nanoparticles were only located on the rGO nanosheets suggesting predominant interaction with the oxygen chemical groups at the surface of this 2D nanomaterial. HRTEM analysis revealed a highly crystalline feature for the $\mathrm{Rh}$ nanoparticles, with a crystalline spacing of 


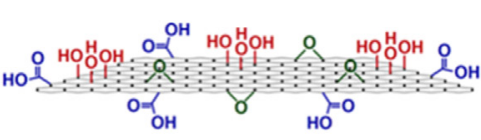

Go

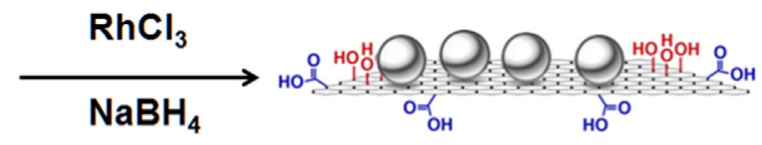

rGO/RhNPs
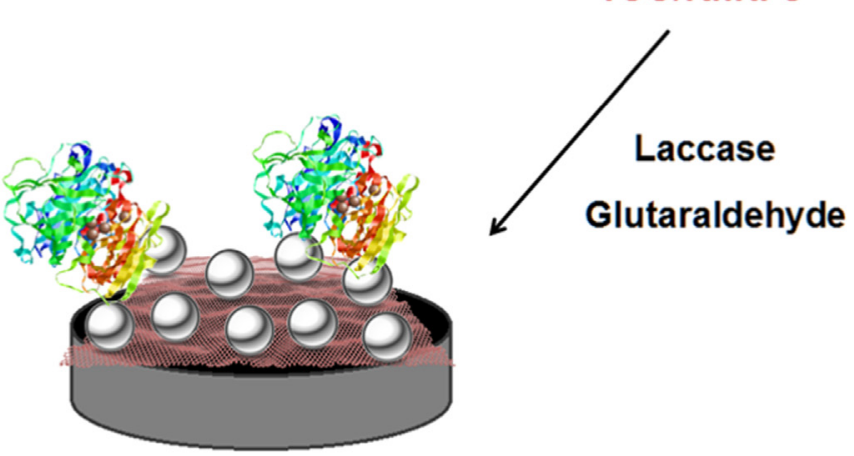

Lac-rGO/RhNPs/GCE

Scheme 1. Preparation of the rGO-RhNP nanocomposite and Lac/rGO-RhNP/GCE biosensor.
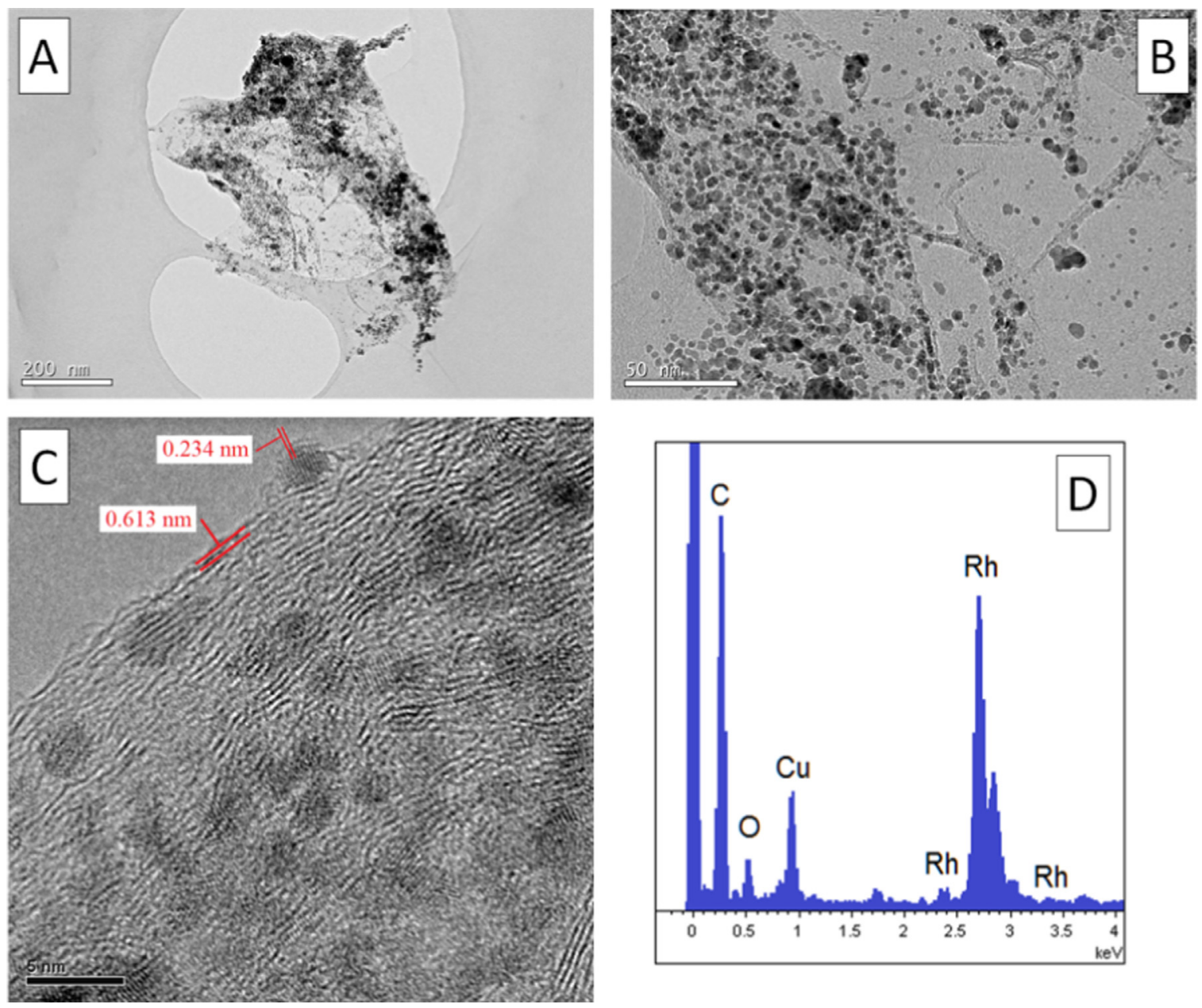

Fig. 1. Representative TEM (A, B) and HRTEM (C) images of rGO-RhNP nanocomposite. EDS analysis of the nanomaterial (D).

$0.234 \mathrm{~nm}$, which can be assigned to $\mathrm{Rh}(111)$ face (Karahan et al., 2012). Moreover, lattice fringes are easily visible at the nanocomposite edges due to folding or rolling of the rGO sheets. The inter-layer spacing between neighboring fringes was determined as $0.613 \mathrm{~nm}$, which is larger than the interplanar spacing in graphite $(0.340 \mathrm{~nm})$, which can be attributed to the bulky metal nanoparticles on the basal plane of the reduced graphene oxide sheets. The presence of Rh nanoparticles was confirmed by energy-dispersive X-ray spectroscopy (EDS) as illustrates in Fig. 1D.

Fig. 2A shows the characterization of the graphene derivatives by FT-IR spectroscopy. GO exhibited a broad peak at $3405 \mathrm{~cm}^{-1}$ corresponding to the stretching of intermolecular $\mathrm{H}$-bonded $\mathrm{O}-\mathrm{H}$ 

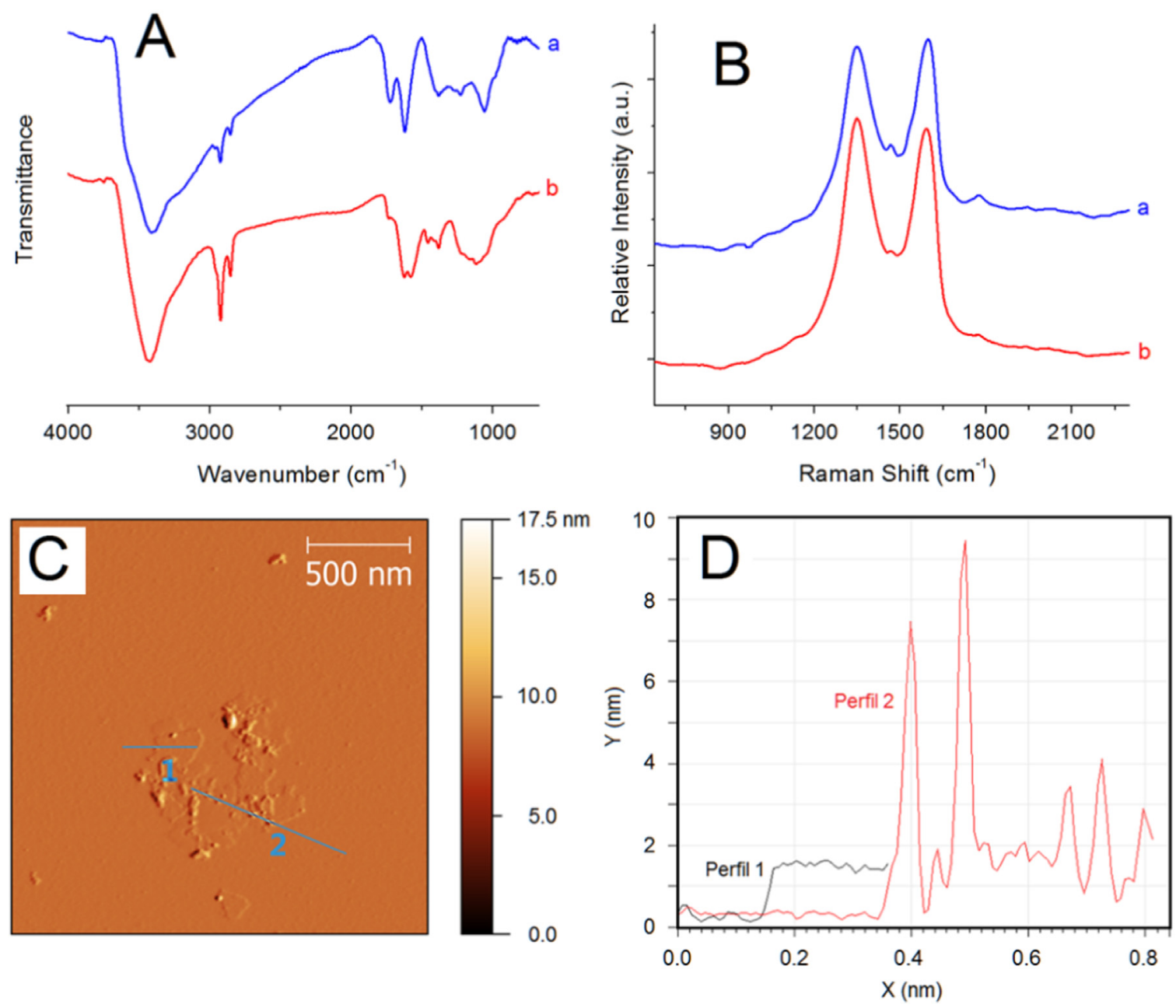

Fig. 2. FT-IR (A), and Raman spectroscopy (B) analysis of GO (a) and rGO-RhNP (b). Representative AFM analysis (C) and AFM profiles (D) of rGO-RhNP nanocomposite.

groups, as well as peaks at $1383 \mathrm{~cm}^{-1}$ and $1228 \mathrm{~cm}^{-1}$ corresponding to the stretching of $\mathrm{C}-\mathrm{OH}$ and $\mathrm{C}-\mathrm{O}-\mathrm{C}$ groups in not oxidized graphitic domains, respectively. The peaks at $1724 \mathrm{~cm}^{-1}$ $\left(v_{\mathrm{C}=\mathrm{O}}\right)$ and $1062 \mathrm{~cm}^{-1}\left(\mathrm{v}_{\mathrm{O}-\mathrm{H}}\right)$ also confirmed the presence of oxygen functional groups in this nanomaterial (Araque et al., 2013). FT-IR analysis was not able to confirm decoration of GO with $\mathrm{Rh}$ nanoparticles. However, partial reduction with $\mathrm{NaBH}_{4}$ was assessed by the noticeable reduction of the intensity of the peaks at $1724 \mathrm{~cm}^{-1}$ and $1228 \mathrm{~cm}^{-1}$ suggesting very low content of carbonyl and epoxy groups in the composite nanomaterial.

Fig. 2B shows the characterization of the graphene derivatives by Raman spectroscopy. GO showed the characteristic G and D bands at $1598 \mathrm{~cm}^{-1}$ and $1347 \mathrm{~cm}^{-1}$ ascribed to the in-phase vibration of the graphite lattice and the structural disorders at the graphite edges, respectively. The $\mathrm{G}$ band was slightly shifted to $1599 \mathrm{~cm}^{-1}$ after reduction with $\mathrm{NaBH}_{4}$ and decoration with $\mathrm{Rh}$ nanoparticles. However, the D/G intensity ratio for GO significantly increased from 0.96 to 1.05 after this transformation, suggesting the interaction between the metal nanoparticles and the graphene sheets, as previously described for other nanoparticles-graphene derivatives (Siamaki et al., 2011; Subrahmanyam et al., 2010).

Topological analysis of the nanocomposite was performed by AFM in tapping mode, and representative results are shown in Fig. 2C,D. Non decorated GO sheets showed planar morphology with $1.3 \mathrm{~nm}$ thickness, in agreement with that reported for this $2 \mathrm{D}$ nanomaterial (Araque et al., 2013; Boujakhrout et al., 2015). The presence of metal nanoparticles was clearly identified by AFM showing colloidal structures with a variety of sizes ranging from
$1 \mathrm{~nm}$ to $8.2 \mathrm{~nm}$. In addition, bulky nanometric aggregates were also observed.

Similar results were achieved by FE-SEM (Fig. 3). The characteristic flat topology of the exfoliated GO sheets was transformed into a more complex nanocomposite material, where colloidal aggregates are detected, by decoration with the metal nanoparticles.

\subsection{Assembly and characterization of the nanostructured enzyme electrode}

The nanocomposite material was evaluated as a scaffold for the design of an electrochemical enzyme biosensor for $17 \beta$-estradiol. As it is illustrated in Scheme 1, the biosensor was assembled by coating glassy carbon electrodes with the rGO-RhNP nanocomposite and further immobilization of the enzyme laccase by using glutaraldehyde as cross-linking agent. It is well know that glutaraldehyde can form stable cross-linking adducts by reaction with many nucleophiles such as amine, thiol, hydroxyl and imidazole groups (Migneault et al., 2004), and this properties has been largely employed to prepare immobilized biocatalysts, polymeric films, microparticles, hydrogels and membranes (Yeh et al. 2015; Zhang et al., 2015; Dos Santos et al., 2015). Scheme 2 displays the linkages that could be formed on the sensing interface by cross-linking the hydroxyl groups at the rGO-RhNP nanocomposite with the primary amino groups at the laccase surface.

However, cross-linking with glutaraldehyde could yield enzyme derivatives with low catalytic activity due to transformation 

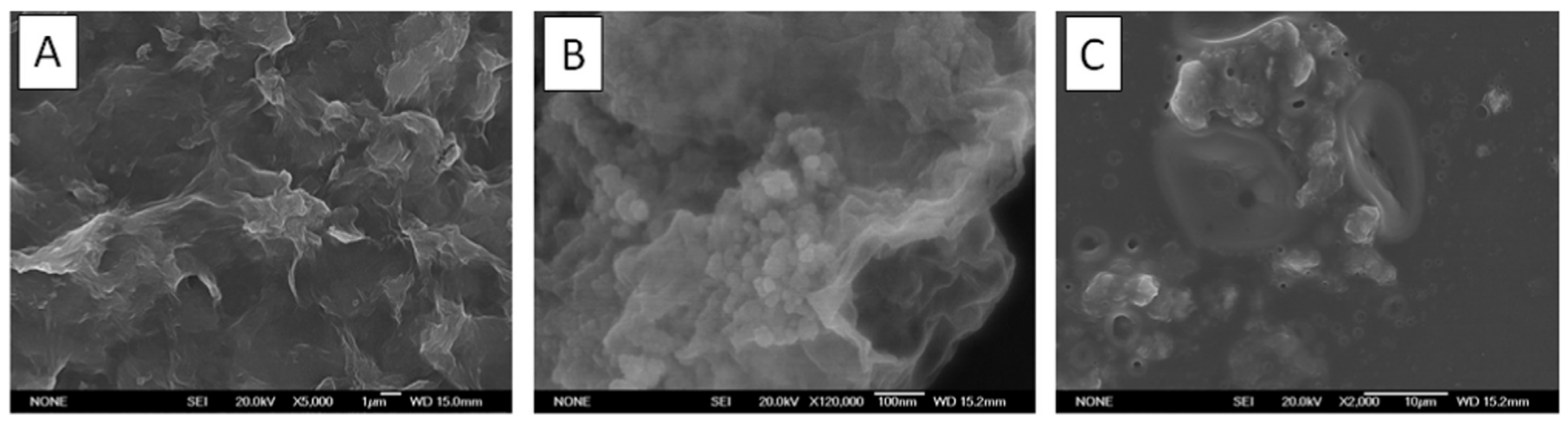

Fig. 3. FE-SEM images of GO (A), rGO-RhNP (B) and Lac/rGO-RhNP/CGE (C).

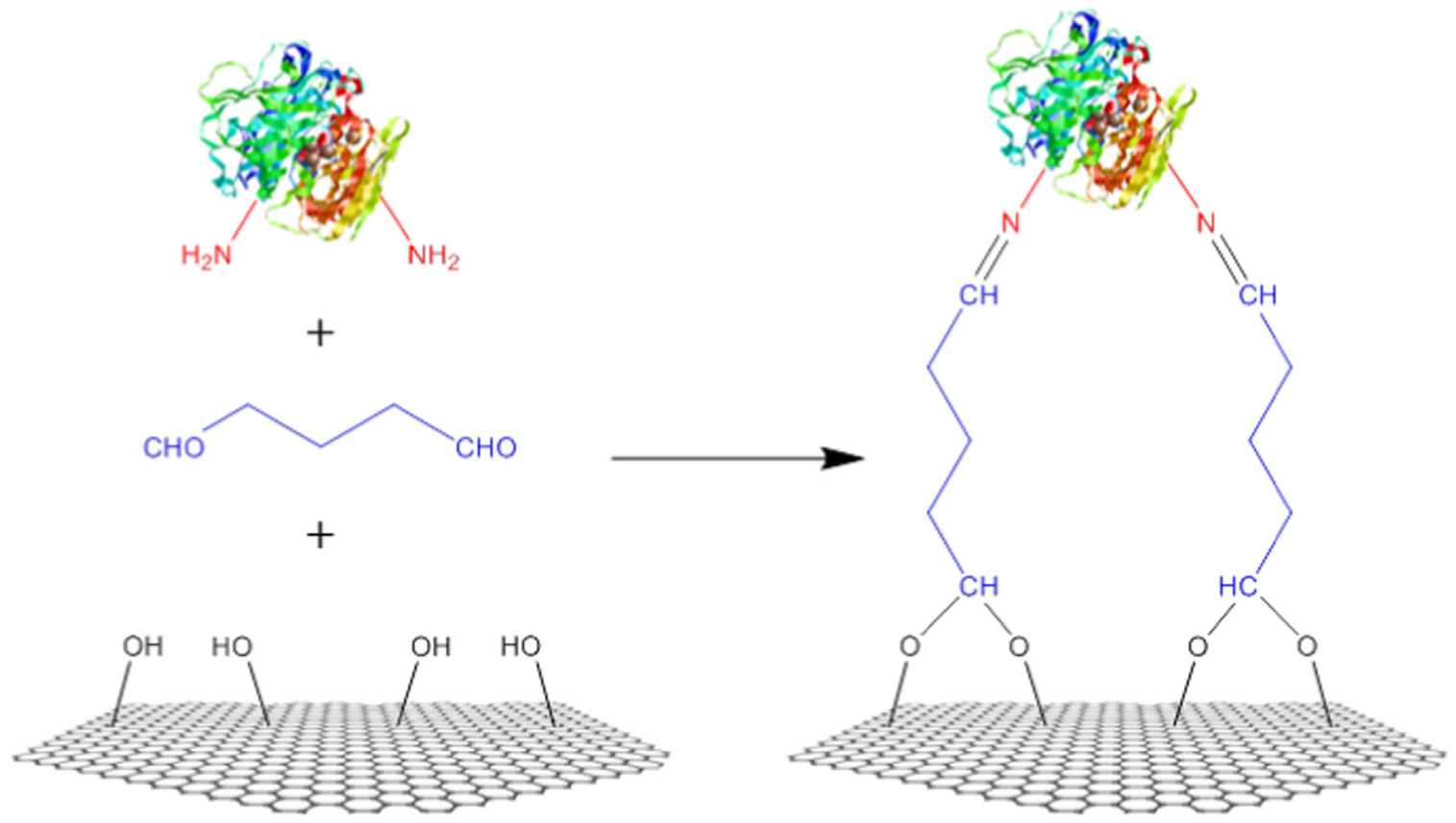

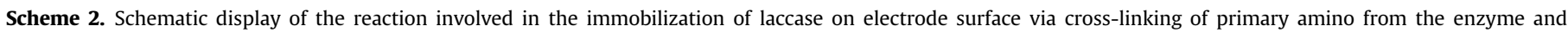
hydroxyl groups from rGO-RhNP nanocomposite with glutaraldehyde.

of essential amino acid residues located at the enzyme active site or by "freezing" the 3D structure of the enzyme (Walt and Agayn, 1994). For this reason, poly(ethylene glycol) diglycidyl ether (PEGDGE) was also evaluated as potential cross-linking agent for the assembly of the laccase electrode. As can be observed in Fig. 1S (Supporting information) remarkably larger voltammetric peaks were achieved by using glutaraldehyde to immobilize the enzyme on the electrode surface. Accordingly, this cross-linker was employed for further experiments.

On the other hand, GCE was selected to assemble the enzyme biosensor due to the high purity, mechanical stability and electrochemical window of this material, as well as the high reproducibility commonly observed for electroanalytical devices using this carbon interface (McCreery, 2008).

The enzyme electrode was further employed to determine $17 \beta$ estradiol by amperometric methods by using thionine as electrochemical mediator. In parallel, an osmium polymer (OsP) based on poly(4-vinylpyridine) bearing $\left.\mathrm{Os}\left(2,2^{\prime} \text {-bipyridine }\right)_{2} \mathrm{Cl}\right]^{2+}$ moieties was also synthesized (Liu and Anzai, 2004) and evaluated as electrochemical mediator. To construct this new modified electrode, $20 \mu \mathrm{L}$ of $0.3 \mathrm{M}$ OsP ethanolic solution was deposited of on the rGO-RhNP/GCE surface, dried at room temperature and used as support for laccase immobilization (Lac/OsP/rGO-RhNP/GCE).
Although this electrode assembly allows the use of thionine as electrochemical mediator in solution to be avoided, the cyclic voltammperometric response of the Lac/OsP/rGO-RhNP/GCE electrode toward $17 \beta$-estradiol was significantly lower than that recorded with Lac/rGO-RhNP/GCE electrode. Moreover, the oxidation peak appeared at noticeably more positive potential value (Fig. 2S, Supporting information). Accordingly, the strategy involving the use of thionine as electrochemical mediator was chosen for further experiments.

The rGO-RhNP coated electrode was characterized by cyclic voltammetry in $0.5 \mathrm{M} \mathrm{HCl}$ solution to evaluate the influence of this nanomaterial on the electrochemical behavior (Fig. 4A). Compared to the GO/GCE, the background current of the rGO-RhNP/GCE increased greatly implying a larger electroconductive surface area of the nanocomposite film on the electrode surface. Two well-defined oxidation peaks at $+410 \mathrm{mV}$ and $+704 \mathrm{mV}$ were also observed, which could be ascribed to the redox transformation of RhNP surface in acid media to $\mathrm{Rh}(\mathrm{I})$ and $\mathrm{Rh}(\mathrm{III})$ adducts, respectively. In addition, the cathodic peak at $+240 \mathrm{mV}$ could be associated to the further reduction of these species to $\operatorname{Rh}(0)$.

The experimental conditions for the assembly of the Lac/rGORhNP/GCE enzyme electrode were optimized by evaluating the influence of different parameters on the differential pulse 

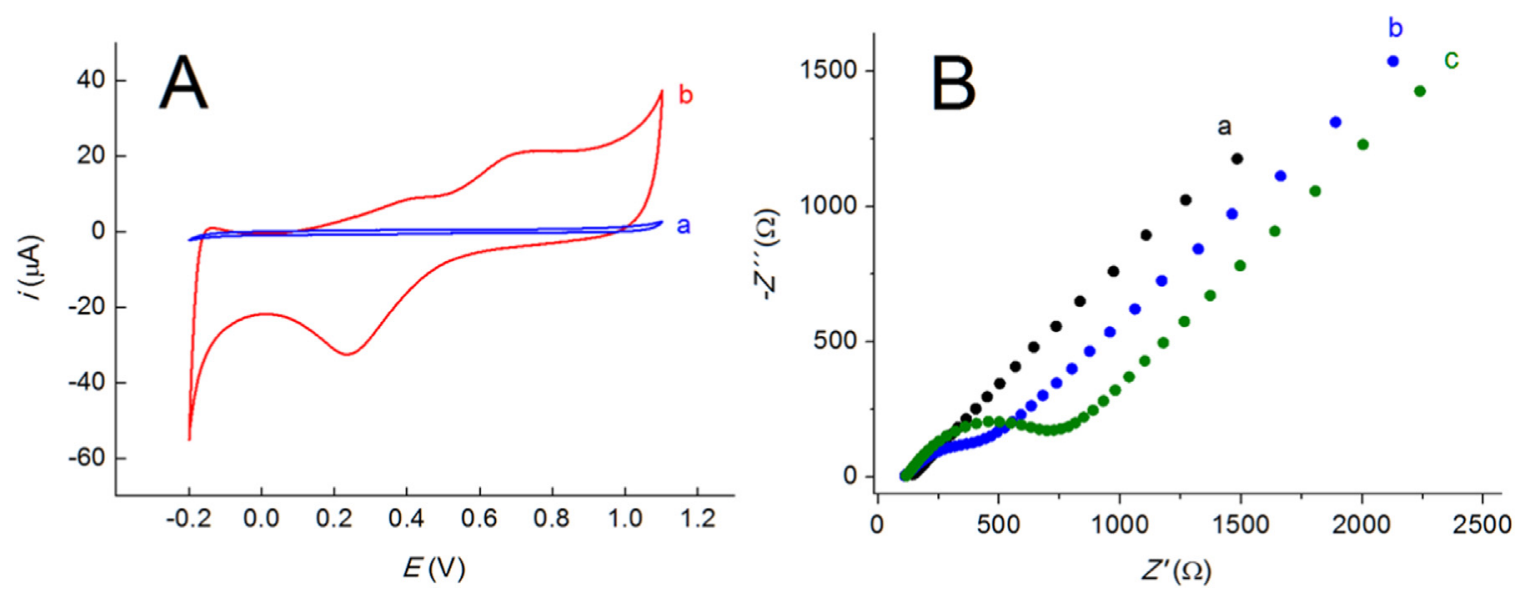

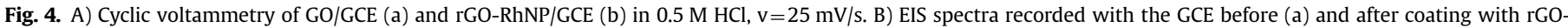
RhNP (b) and Lac/rGO-RhNP in $0.1 \mathrm{M} \mathrm{KCl}$ solution containing $5 \mathrm{mM} \mathrm{K}_{3}\left[\mathrm{Fe}(\mathrm{CN})_{6}\right] / \mathrm{K}_{4}\left[\mathrm{Fe}(\mathrm{CN})_{6}\right](1: 1)$.

voltammetric (DPV) biosensor response toward $0.5 \mu \mathrm{M} 17 \beta$-estradiol in $0.1 \mathrm{M}$ sodium phosphate buffer, $\mathrm{pH} 7.0$ containing $1 \mathrm{mM}$ thionine as electrochemical mediator. These measurements were performed using the following DPV conditions: modulation amplitude $=75 \mathrm{mV}$, and step potential $=1 \mathrm{mV}$. As is reported in Fig. 3S (Supporting information), larger analytical responses were achieved by coating the electrodes with $5 \mu \mathrm{g}$ of nanocomposite and immobilization of $66 \mu \mathrm{g}$ laccase by using 3\% (v/v) glutaraldehyde as cross-linking agent.

The assembly of the electrode under such optimal conditions was studied by electrochemical impedance spectroscopy (EIS) using $\left[\mathrm{Fe}(\mathrm{CN})_{6}\right]^{4-/ 3-}$ as redox probe (Fig. 4B). The experimental data were obtained by fitting with a conventional Randles equivalent circuit. Modification of the GCE with the nanocomposite slightly increased the electron transfer resistance of the interface (from $R_{\mathrm{et}}=113 \Omega$ to $\mathrm{R}_{\mathrm{et}}=132 \Omega$ ). A relative large increase in the $R_{\text {et }}$ value, $538 \Omega$, was noticed after cross-linking of laccase with glutaraldehyde indicating the successful attachment of the enzyme on the sensing surface. This fact was also confirmed by FESEM (Fig. 3C), showing that the enzyme-modified electrode exhibited a smooth and homogeneous morphology which could be ascribed to a high protein loading on the electrode surface.

The electroanalytical behavior of this nanostructured enzyme electrode toward $17 \beta$-estradiol was studied by cyclic voltammetry and DVP using thionine as electrochemical mediator. As control experiments, voltammmograms with GCEs modified with other combinations of the biosensing interface components were also recorded. As can be observed in Fig. 5, all electrodes showed voltammetry responses, which can be ascribed to the electrochemical transformation of thionine on the electrode surface. The presence of RhNP on the sensing interface caused an electrocatalytic effect on the analytical determination of $17 \beta$-estradiol by reducing the potential at which the voltammetry peaks can be measured. In addition, a new peak around $0.0 \mathrm{~V}$ was clearly observed in DP voltammograms of the Lac/rGO-RhNP/GCE and Lac/rGO-RhNP/GCE electrodes, which should be ascribed to the presence of RhNP on the composite nanomaterial (Fig. 5B, curves d-e; Fig. 4S). rGORhNP electrode showed a relevant response toward $17 \beta$-estradiol, which was similar to those obtained with a control enzyme electrode prepared by using thermal inactivated laccase (data not shown). However, large electrochemical signals were obtained by combining active laccase and the rGO-RhNP nanocomposite material on the sensing surface, demonstrating that the enzyme is needed for an efficient electrocatalytic transformation of $17 \beta$-estradiol, and accordingly, the proposed interface architecture is a good choice for the development of an electrochemical biosensor for this hormone.

To ensure that the analytical signal recorded with the enzyme electrode is related to the laccase-mediated transformation of $17 \beta$ estradiol in the presence of thionine in solution, a control experiment was performed by recording cyclic voltammograms at the Lac/rGO-RhNP/GCE electrode before and after addition of the
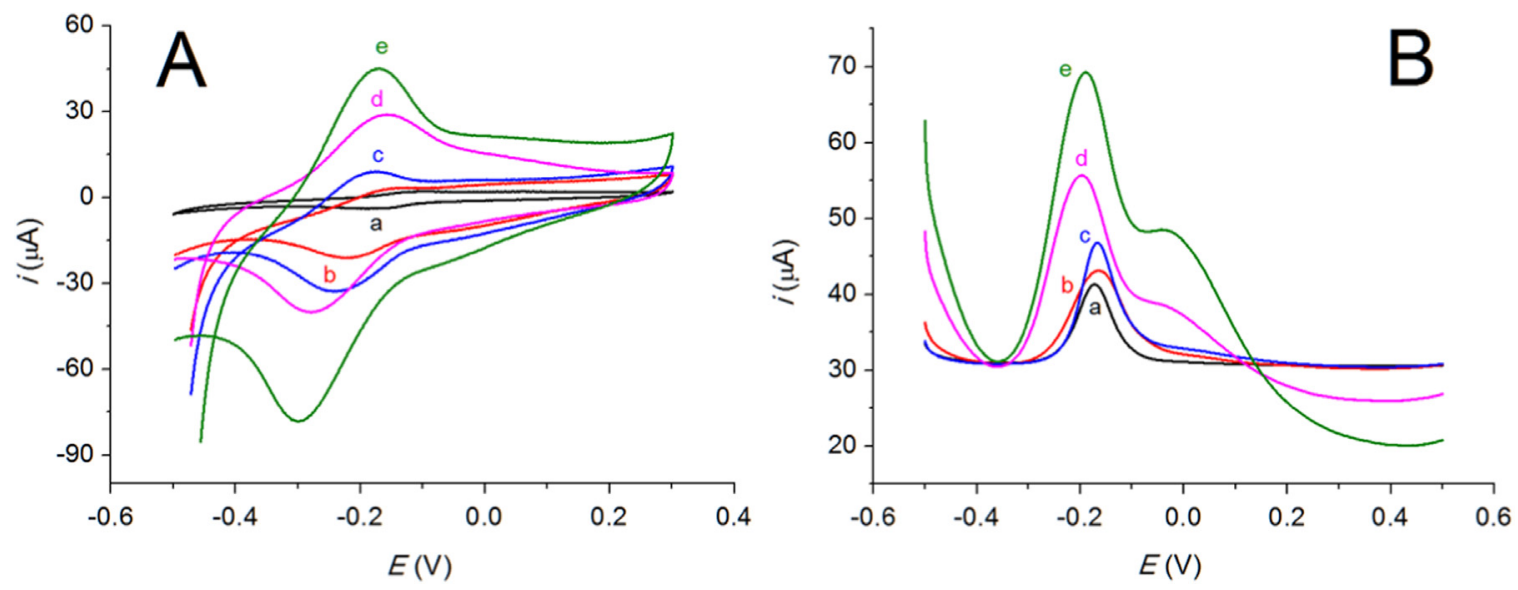

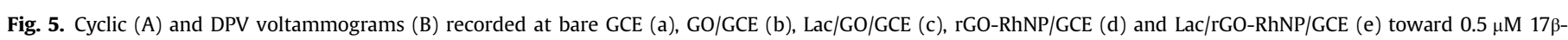

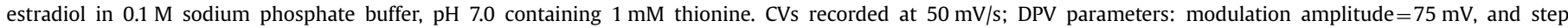
potential $=1 \mathrm{mV}$. 


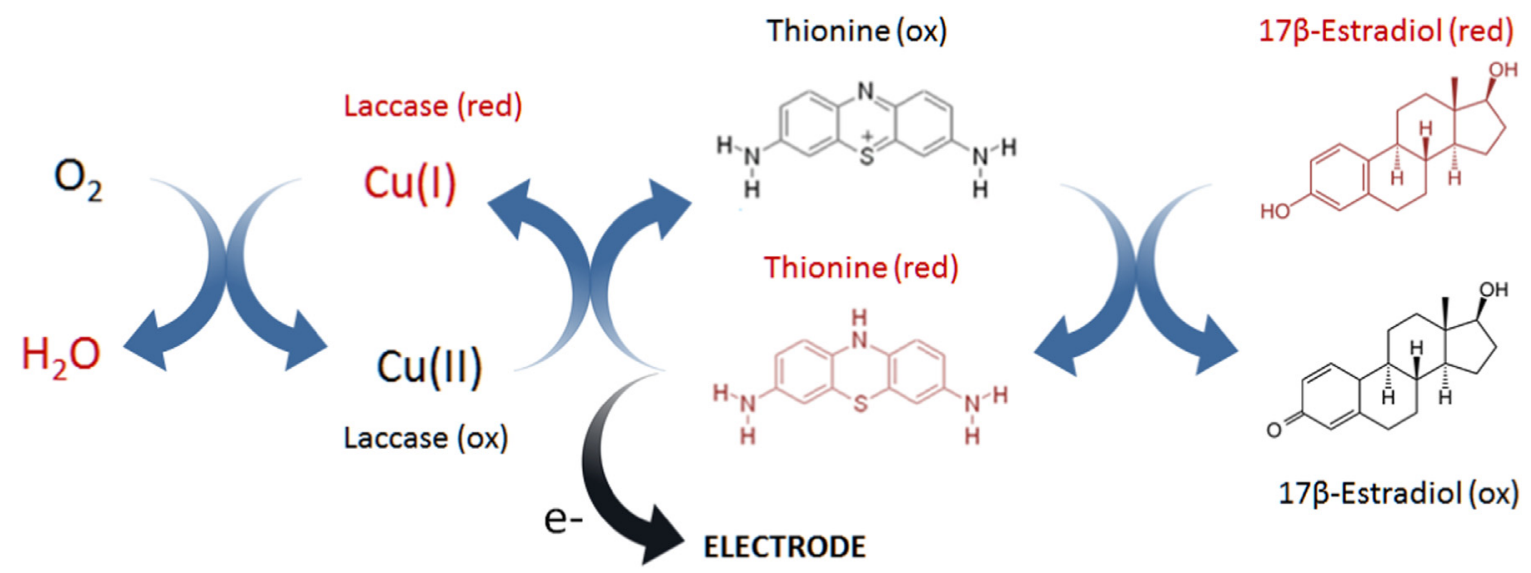

Scheme 3. Schematic display of the electrocatalytic mechanism proposed for the enzyme biosensor.

hormone. As is illustrated in Fig. 5S (Supporting information), no significant response was observed in $1 \mathrm{mM}$ thionine solutions in $0.1 \mathrm{M}$ sodium phosphate buffer, $\mathrm{pH}$ 7.0. However, well-defined redox peaks, with peak height increasing with hormone concentration, were observed after addition of $17 \beta$-estradiol. These cyclic voltammetry experiments were performed at low scan rates to see more visible the effect of $17 \beta$-estradiol concentration on the resulting peaks.

It was also demonstrated that the determination of $17 \beta$-estradiol can be performed at very low potential value when thionine was used as electrochemical mediator (Fig. 4S).

Scheme 3 illustrates the proposed electrocatalytic mechanism involved in the enzyme-mediated transformation of $17 \beta$-estradiol at the electrode surface by using thionine as electrochemical mediator. Through this mechanism, $17 \beta$-estradiol can be detected at relative low working potential due to the capacity of thionine to mediate the transformation of this hormone at the nanostructured enzyme electrode surface.

Taking into account the larger electroanalytical responses obtained by DPV, further biosensing measurements were performed by using this electrochemical method. The optimization studies for the DPV electrochemical biosensing of $17 \beta$-estradiol are reported in Fig. 6S (Supporting information). Interestingly, higher analytical signals were recorded by using $0.1 \mathrm{M}$ sodium phosphate buffer, $\mathrm{pH}$ 7.0 (Fig. 6S-A). It should be remember that the optimum $\mathrm{pH}$ for the catalytic activity of non-immobilized $T$. versicolor laccase lie generally in the acidic region, typically in the range of 3.5-6, depending on the substrate (Kurniawati and Nicell, 2008). Accordingly, the $\mathrm{pH}$-activity profile in Fig. 6S-A could be caused by:

i) An increase in the electrocatalytic behavior of the enzyme at neutral pH upon immobilization, and/or

ii) A fast electrochemical transformation of some reactants/products of the enzyme-catalyzed reaction taking place under neutral conditions.

To clarify this issue, the effect of $\mathrm{pH}$ on the analytical signal of the rGO-RhNP/GCE electrode toward $17 \beta$-estradiol was measured by DPV, by also adding laccase to the reaction mixture. As can be observed in Fig. 7S, high electroanalytical signal was recorded by using free enzyme at $\mathrm{pH}$ 6.0. This fact suggest that immobilization of the enzyme on the nanostructured surface in Lac/rGO-RhNP/ GCE electrode causes relevant changes at the microenvironment of the immobilized enzyme, then shifting the optimum $\mathrm{pH}$ to neutral values. Similar behavior has been previously reported for other enzymes upon immobilization or covalent modification with macromolecular and olimeric compounds (Gómez et al. 2006;
Villalonga et al., 2014).

It was also demonstrated that larger peak currents were measured with $1.0 \mathrm{mM}$ thionine concentration (Fig. 6S-B) as well as for a DPV modulation amplitude of $75 \mathrm{mV}$ and a step potential of $1 \mathrm{mV}$ (Fig. 6S-C,D). Accordingly, further these working conditions were selected for further measurements.

Fig. 6A shows typical DP voltammograms recorded at the nanostructured enzyme electrode upon successive additions of $17 \beta$ estradiol. The current peak values increased with the hormone concentration exhibiting a linear behavior $(r=0.997)$ over the $0.9-11 \mathrm{pM}$ concentration range, according to the following equation:

$i(\mathrm{~A})=(1.8 \pm 0.3) \cdot 10^{6} \cdot \mathrm{c}(17 \beta$-Estradiol $/ \mathrm{M})+(1.42 \pm 0.03) \cdot 10^{-5}$

This range of linear response was narrower than other previously reported for electrochemical biosensors for $17 \beta$-estradiol based on affinity bioreceptors (Table 1). However, it ensures the accurate determination of the hormone at the picomolar concentration level.

The enzyme biosensor showed a high sensitivity of $1.8 \mathrm{~A} / \mu \mathrm{M}$ $\left(25.7 \mathrm{~A} / \mu \mathrm{M} \mathrm{cm}^{2}\right)$, which was estimated by using the electroactive surface area of the Lac/rGO-RhNP/GCE calculated through the Randles-Sevcik equation. This high sensitivity can be attributed to the large electroactive surface area of the modified electrode, the synergic electrocatalytic effect of RhNPs and laccase for $17 \beta$-estradiol oxidation, and the occurrence of fast electron transfer between the enzyme and the electrode surface due to the high electroconductive and low barrier properties of the 3D assembled hybrid nanomaterial.

A very low detection limit of $0.54 \mathrm{pM} 17 \beta$-estradiol was estimated for this biosensor. This value was calculated according to the $3 S_{b} / m$ criterion, where $m$ is the slope of the calibration curve and $S_{b}$ was estimated as the standard deviation of 10 different DPV signals recorded for the lowest $17 \beta$-estradiol concentration measured in the calibration graph $(0.9 \mathrm{pM})$. As can be observed in Table 1, this low limit of detection ranks among the best obtained for the electrochemical detection of the hormone. However our enzyme-based device is characterized by a simple design, low cost and easy operation, in contrast with those affinity-based biosensors previously described.

These excellent analytical properties could be associated to the use of rGO-RhNP as nanostructured scaffold for the covalent immobilization of the enzyme. To support this hypothesis, the apparent kinetics constants for the immobilized enzyme were calculated by means of the Lineweaver-Burk plots. The obtained values were $9.9 \mathrm{pM}$ and $68 \mu \mathrm{A}$ for $K_{M}$ and $I_{M A X}$, respectively. This very low apparent $K_{M}$ value suggests that rGO-RhNP provides a favourable microenvironment for the laccase-mediated 

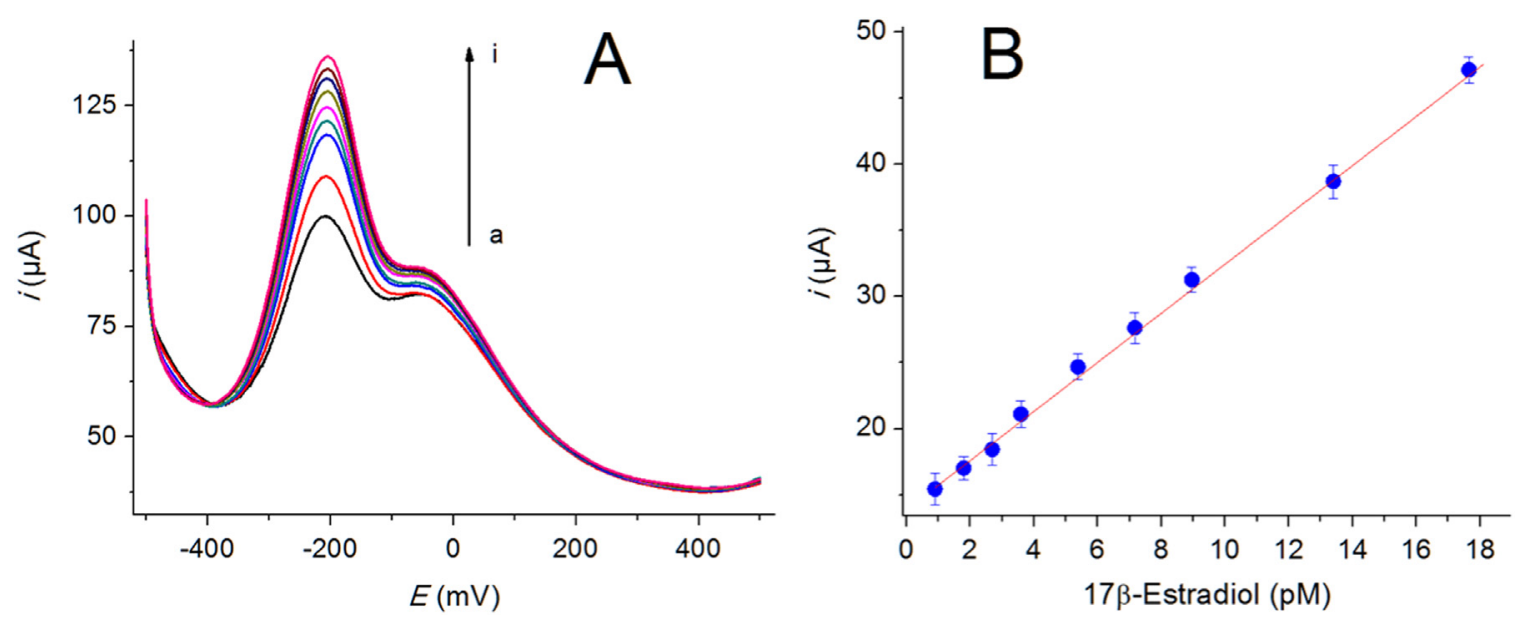

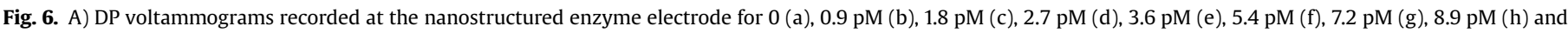
$11.0 \mathrm{pM}$ (i) $17 \beta$-estradiol. B) Calibration curve constructed for $17 \beta$-estradiol at the Lac/rGO-RhNP/GCE biosensor.

transformation of $17 \beta$-estradiol on the electrode surface.

The reproducibility of the biosensor toward successive additions of $17 \beta$-estradiol was examined in the $1.8 \mathrm{pM}$ to $5.4 \mathrm{pM}$ range. The R.S.D. for the slope values measured with10 different calibration graphs was 3.4\%. In addition, the biosensor-to-biosensor reproducibility was evaluated by measuring the slope values of the calibration plots constructed with 5 different biosensors prepared in the same manner. The R.S.D. value was $8.2 \%$ indicating good reproducibility for the procedure employed to assemble the enzyme biosensor.

It should be noted that this biosensor was also evaluated for the amperometric detection of $17 \beta$-estradiol in continuous mode by using flow injection arrangement. Higher analytical response was achieved by setting the working potential at $-220 \mathrm{mV}$. The biosensor was able to detect this hormone over the $3.6-270 \mu \mathrm{M}$ concentration range according to the following equation (Fig. 8S-A in Supporting information):

$\mathrm{i}(\mathrm{A})=(104 \pm 60) \cdot \mathrm{c}(17 \beta-$ Estradiol $/ M)+(6.2 \pm 0.8) \cdot 10^{-4}$

However, the amperometric response showed a progressive decrease in the current peak as it is illustrated in Fig. 8S-B (Supporting information), thus suggesting a poorer stability of the biosensor under continuous flow conditions.

The selectivity of the biosensor was evaluated by measuring the DPV responses generated by 8 different potential interfering substances at $50 \mathrm{pM}$ concentration, and comparing with that obtained for $5 \mathrm{pM} 17 \beta$-estradiol under similar measuring conditions. Very low analytical signals were recorded for ascorbic acid $(0.7 \%)$, hydroquinone (1.0\%), dopamine (1.2\%), bisphenol A (1.6\%), catechol (1.9\%), progesterone (2.1\%), estriol (2.2\%) and ethinyl estradiol $(2.7 \%)$, suggesting a high selectivity of the nanostructured enzyme biosensor for $17 \beta$-estradiol.
The long-term stability of the biosensor was estimated by storing the enzyme electrode at $4{ }^{\circ} \mathrm{C}$ under dry conditions. The electrode was periodically tested by measuring the analytical response in the whole linear range of response for $17 \beta$-estradiol, and the slope of the resulting calibration curves were compared with those obtained the first day of use (Fig. 9S in Supporting information). The biosensor retained more than $96 \%$ of the initial electroanalytical activity after one week of storage, but longer times at $4{ }^{\circ} \mathrm{C}$ produced a progressive loss of analytical response reaching about $83 \%$ and $54 \%$ of the initial activity after two and four weeks of storage, respectively.

Human urine is a major source of endocrine disrupting compounds released to the environment (Petrović et al., 2001). On the other hand, the determination of the main biologically active estrogens, such as $17 \beta$-estradiol, in urinary samples is relevant to evaluate the action and malfunction of endocrine glands, and accordingly, to detect potential endocrine disorders that are commonly associated with many diseases such as breast cancer, anorexia nervosa, and pseudohermaphroditism (Zou et al., 2012). For these reasons, the nanostructured enzyme biosensor was employed to determine the $17 \beta$-estradiol content in spiked real and synthetic (Urine Chemistry Control, BIO-RAD, USA) urine samples. To do that, urine samples were spiked with $17 \beta$-estradiol, properly diluted and measured with the nanostructured biosensor (Fig. 10S in Supporting information). High recovery values of $99.6 \pm 0.8 \%$ and $98.9 \pm 0.6 \%$ were obtained for real and synthetic urine samples, demonstrating the analytical reliability of the proposed electrochemical device to quantify $17 \beta$-estradiol in real samples.

Table 1

Comparison of the analytical performance of relevant electrochemical biosensors for $17 \beta$-estradiol.

\begin{tabular}{|c|c|c|c|c|}
\hline Electrode & Bioreceptor/Method & Linear Range (pM) & LOD (pM) & Reference \\
\hline Apt-Au & Aptamer/EIS & $10-10^{4}$ & 2 & Lin et al., 2012 \\
\hline $\mathrm{ER} \alpha / \mathrm{BSA} / \mathrm{Au}$ & $\mathrm{ER} \alpha / \mathrm{EIS}$ & $0.1-10^{3}$ & 0.1 & Kim et al., 2012 \\
\hline Apt/AuNP/CuS/GCE & Aptamer/DPV & $0.1-10^{3}$ & 0.7 & Huang et al., 2015a \\
\hline Apt/AuD/BDDE & Aptamer/EIS & $10^{-2}-10^{3}$ & 0.005 & Ke et al., 2014 \\
\hline E2/PAMAM-AuNP/ rGO-PANI/GCE & Antibody (competitive)/DPV & $0.15-26$ & 0.07 & Li et al., 2013 \\
\hline Apt/WS $\mathrm{W}_{2} / \mathrm{AuNP} / \mathrm{GCE}$ & Aptamer/DPV & $10-5 \cdot 10^{3}$ & 2 & Huang et al., 2014 \\
\hline $\mathrm{Lac} / \mathrm{rGO}-\mathrm{RhNP} / \mathrm{GCE}$ & Enzyme/DPV & $0.9-11$ & 0.54 & This work \\
\hline
\end{tabular}

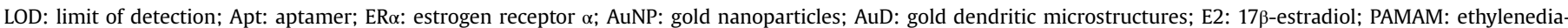
mine-core polyamidoamine dendrimer; PANI: polyaniline; SWV: square wave voltammetry. 


\section{Conclusions}

A novel nanocomposite material was prepared by in situ reduction and decoration of graphene oxide with rhodium nanoparticles. This nanomaterial was employed to modify GCE and then used as scaffold to immobilize the enzyme laccase on the electrode surface through a glutaraldehyde-mediated cross-linking reaction. This enzyme electrode was employed to construct a voltammperometric biosensor for $17 \beta$-estradiol which exhibited high sensitivity, selectivity and reproducibility, and was able to detect the hormone at picomolar concentration levels. This electrochemical biosensor was successfully used to detect $17 \beta$-estradiol in spiked real and synthetic urine samples with high recovery values. Attending to these results, we suggest the use of this $2 \mathrm{D}$ composite nanomaterial as an excellent tool to prepare sensitive and reliable oxidase-based enzyme biosensors for endocrine disrupting compounds.

\section{Conflict of interest}

The authors declare no conflict of interest.

\section{Acknowledgements}

Financial support from the Spanish Ministry of Economy and Competitiveness CTQ2014-58989-P, CTQ2011-24355, CTQ201571936-REDT, CTQ2012-34238 and Comunidad de Madrid S2013/ MIT-3029, Programme NANOAVANSENS is gratefully acknowledged.

\section{Appendix A. Supporting information}

Supplementary data associated with this article can be found in the online version at doi:10.1016/j.bios.2016.07.018.

\section{References}

Allen, MJ., Tung V.C., Kaner, R.B., 2009. Chem. Rev, 110, 132-145.

Araque, E., Villalonga, R., Gamella, M., Martínez-Ruiz, P., Sánchez, A., García-Baonza, V., Pingarrón, J.M., 2014a. ChemPlusChem 79, 1334-1341.

Araque, E., Arenas, C.B., Gamella, M., Reviejo, J., Villalonga, R., Pingarrón, J.M., 2014b. J. Electroanal. Chem. 717, 96-102.

Araque, E., Villalonga, R., Gamella, M., Martínez-Ruiz, P., Reviejo, J., Pingarrón, J.M., 2013. J. Mater. Chem. B 1, 2289-2296.

Borisova, B., Ramos, J., Díez, P., Sánchez, A., Parrado, C., Araque, E., Villalonga, R., Pingarrón, J.M., 2015. Electroanalysis 27, 2131-2138.

Boujakhrout, A., Sánchez, A., Díez, P., Jiménez-Falcao, S., Martínez-Ruiz, P., PeñaÁlvarez, M., Pingarrón, J.M., Villalonga, R., 2015. J. Mater. Chem. B 3, 3518-3524.

De Assis, S., Wang, M., Jin, L., Bouker, K.B., Hilakivi-Clarke, L.A., 2013. Cancer Prev. Res. 6, 1194-1211.

Dos Santos, J.C., Rueda, N., Sanchez, A., Villalonga, R., Gonçalves, L.R., FernandezLafuente, R., 2015. RSC Adv, 5, 35801-35810.

Fernández, I., Sánchez, A., Díez, P., Martínez-Ruiz, P., Di Pierro, P., Porta, R., Villalonga, R., Pingarrón, J.M., 2014. Chem. Commun. 50, 13356-13358.

Gómez, L., Ramírez, H.L., Villalonga, M.L., Hernández, J., Villalonga, R., 2006. Enzym.
Microb. Technol. 38, 22-27.

Huang, K.J., Liu, Y.J., Zhang, J.Z., 2015a. Microchim. Acta 182, 409-417.

Huang, K.J., Liu, Y.J., Zhang, J.Z., Liu, Y.M., 2014. Anal. Methods 6, 8011-8017.

Huang, K.J., Liu, Y.J., Zhang, J.Z., Cao, J.T., Liu, Y.M., 2015b. Biosens. Bioelectron. 67, 184-191.

Hummers Jr, W.S., Offeman, R.E., 1958. J. Am. Chem. Soc. 80, 1339, 1339.

Kailashiya, J., Singh, N., Singh, S.K., Agrawal, V., Dash, D., 2015. Biosens. Bioelectron. 65, 274-280.

Kannan, P.K., Late, D.J., Morgan, H., Rout, C.S., 2015. Nanoscale 7, 13293-13312.

Karahan, S., Zahmakiran, M., Özkar, S., 2012. Chem. Commun. 48, 1180-1182.

Ke, H., Liu, M., Zhuang, L., Li, Z., Fan, L., Zhao, G., 2014. Electrochim. Acta 137, $146-153$.

Khatayevich, D., Page, T., Gresswell, C., Hayamizu, Y., Grady, W., Sarikaya, M., 2014. Small 10, 1505-1513.

Kim, B.K., Li, J., Im, J.E., Ahn, K.S., Park, T.S., Cho, S.I., Kim, Y.R., Lee, W.Y., 2012. J. Electroanal. Chem. 671, 106-111.

Kurniawati, S., Nicell, J.A., 2008. Bioresour. Technol. 99, 7825-7834.

Lei, J., Ju, H., 2012. Chem. Soc. Rev. 41, 2122-2134.

Li, J., Liu, S., Yu, J., Lian, W., Cui, M., Xu, W., Huang, J., 2013. Sens. Actuators B Chem. 188, 99-105.

Lian, Y., He, F., Wang, H., Tong, F., 2015. Biosens. Bioelectron. 65, 314-319.

Lin, Z., Chen, L., Zhang, G., Liu, Q., Qiu, B., Cai, Z., Chen, G., 2012. Analyst 137, 819-822.

Liu, A., Anzai, J.I., 2004. Anal. Chem. 76, 2975-2980.

Liu, Y., Dong, X., Chen, P., 2012. Chem. Soc. Rev. 41, 2283-2307.

McCreery, R.L., 2008. Chem. Rev. 108, 2646-2687.

Mei, L.P., Feng, J.J., Wu, L., Zhou, J.Y., Chen, J.R., Wang, A.J., 2015. Biosens. Bioelectron, $74,347-352$

Migneault, I., Dartiguenave, C., Bertrand, M.J., Waldron, K.C., 2004. Biotechniques 37, 790-806.

Petrović, M., Eljarrat, E., de Alda, M.J.L., Barceló, D., 2001. Trends Anal. Chem. 20, 637-648.

Riva, S., 2006. Trends Biotechnol. 24, 219-226.

Rourke, J.P., Pandey, P.A., Moore, J.J., Bates, M., Kinloch, I.A., Young, R.J., Wilson, N.R., 2011. Angew. Chem. Int. Ed. 123, 3231-3235.

Saadaoui, M., Fernández, I., Sánchez, A., Díez, P., Campuzano, S., Raouafi, N., Pingarrón, J.M., Villalonga, R., 2015. Electrochem. Commun. 58, 57-61.

Sarkar, D., Liu, W., Xie, X., Anselmo, A.C., Mitragotri, S., Banerjee, K., 2014. ACS Nano 8, 3992-4003.

Siamaki, A.R., Khder, A.E.R.S., Abdelsayed, V., El-Shall, M.S., Gupton, B.F., 2011. J. Catal. 279, 1-11.

Storgaard, L., Bonde, J.P., Olsen, J., 2006. Reprod. Toxicol. 21, 4-15.

Subrahmanyam, K.S., Manna, A.K., Pati, S.K., Rao, C.N.R., 2010. Chem. Phys. Lett. 497, 70-75.

Suzuki, K., Hirai, H., Murata, H., Nishida, T., 2003. Water Res. 37, 1972-1975.

Torres-Duarte, C., Viana, M.T., Vazquez-Duhalt, R., 2012. Appl. Biochem. Biotechnol. $168,864-876$.

Vasilescu, I., Eremia, S.A., Kusko, M., Radoi, A., Vasile, E., Radu, G.L., 2016. Biosens. Bioelectron. 75, 232-237.

Villalonga, M.L., Díez, P., Sánchez, A., Gamella, M., Pingarrón, J.M., Villalonga, R., 2014. Chem. Rev. 114, 4868-4917.

Walcarius, A., Minteer, S.D., Wang, J., Lin, Y., Merkoçi, A., 2013. J. Mater. Chem. B 1, $4878-4908$.

Walt, D.R., Agayn, V.I., 1994. Trends Anal. Chem. 13, 425-430.

Wang, L., Wang, Y., Wong, J.I., Palacios, T., Kong, J., Yang, H.Y., 2014. Small 10, 1101-1105.

Yáñez-Sedeño, P., Villalonga, R. Pingarrón, J.M., 2015. Encyclopedia of Analytical Chemistry. pp. 1-18.

Yang, Z., Ren, Y., Zhang, Y., Li, J., Li, H., Hu, X.H.X., Xu, Q., 2011. Biosens. Bioelectron. 26, 4337-4341.

Yeh, J.T., Hou, Y.J., Cheng, L., Wang, Y.Z., Yang, L., Wang, C.K., 2015. Carbohydr. Polym. 127, 135-144.

Ying, G.G., Kookana, R.S., Ru, Y.J., 2002. Environ. Int. 28, 545-551.

Yuan, Y., Li, R., Liu, Z., 2014. Anal. Chem. 86, 3610-3615.

Zhang, X., Sun, P., Huangshan, L., Hu, B.H., Messersmith, P.B., 2015. Chem. Commun. 51, 9662-9665.

Zhao, H., Ji, X., Wang, B., Wang, N., Li, X., Ni, R., Ren, J., 2015. Biosens. Bioelectron. 65, 23-30.

Zou, Y., Li, Y., Jin, H., Tang, H., Zou, D., Liu, M., Yang, Y., 2012. Anal. Biochem. 421, 378-384. 